14

\title{
Незаполненные электронные состояния ультратонких пленок дифенилфталида на поверхности высокоупорядоченного пиролитического графита
}

\author{
(C) А.С. Комолов ${ }^{1}$, Э.Ф. Лазнева ${ }^{1}$, Н.Б. Герасимова ${ }^{1}$, В.С. Соболев ${ }^{1}$, С.А. Пшеничнюк ${ }^{2}$, \\ Н.Л. Асфрандиаров ${ }^{2}$, В.А. Крайкин ${ }^{3}$, В. Handke ${ }^{4}$ \\ ${ }^{1}$ Санкт-Петербургский государственный университет, \\ С.-Петербург, Россия \\ ${ }^{2}$ Институт физики молекул и кристаллов - обособленное структурное подразделение Уфимского фредерального \\ исследовательского центра РАН, \\ Уфа, Россия \\ ${ }^{3}$ Уфимский институт химии - \\ обособленное структурное подразделение Уфимского федерального исследовательского центра РАН, \\ Уфра, Россия \\ ${ }^{4}$ AGH University of Science and Technology, Faculty of Material Science and Ceramics, \\ Kraków, Poland \\ E-mail: a.komolov@spbu.ru
}

Поступила в Редакцию 29 мая 2019 г.

В окончательной редакции 29 мая 2019 г.

Принята к публикации 11 июня 2019 г.

\begin{abstract}
Приведены результаты диагностики атомного состава термически осажденной в вакууме пленки дифенилфталида (DPP) методом рентгеновской фотоэлектронной спектроскопии (XPS). Приведены результаты исследования незаполненных электронных состояний ультратонких пленок DPP толщиной до $10 \mathrm{~nm}$ на поверхности высокоупорядоченного пиролитического графита (HOPG) методом спектроскопии полного тока (TCS) в энергетическом диапазоне от 5 до $20 \mathrm{eV}$ выше $E_{\mathrm{F}}$. В этом диапазоне установлены основные максимумы в спектрах полного тока. Анализ TCS результатов с учетом результатов теоретических расчетов показал, что низкоэнергетические максимумы, наблюдаемые при энергиях 6 и $7.5 \mathrm{eV}$, образованы преимущественно $\pi^{*}$ электронными орбиталями пленок DPP. Экспериментально установленные значения энергии $E_{\mathrm{vac}}$ относительно $E_{\mathrm{F}}$, то есть электронной работы выхода пленок DPP при толщине пленки 5-10 nm, составляют $4.3 \pm 0.1 \mathrm{eV}$. Формированию пограничного барьера HOPG/DPP в процессе термического осаждения пленки DPP соответствует перенос отрицательного заряда из органической пленки в подложку.
\end{abstract}

Ключевые слова: сопряженные органические молекулы, ультратонкие пленки, электронные свойства, низкоэнергетическая электронная спектроскопия, пограничный потенциальный барьер.

DOI: $10.21883 /$ FTT.2019.10.48277.497

\section{1. Введение}

Среди материалов органической электроники выделяют класс материалов на основе молекул фталидов и их производных [1-3]. Структурная формула молекул дифенилфталидов, исследованных в данной работе, представлена на рис. 1. Электропроводность тонких пленок фталидов обусловлена формированием электронных состояний в запрещенной зоне этих материалов при разрыве ковалентной связи С-O в составе пятичленного цикла в молекуле (рис. 1) [4,5]. Причем электропроводность пленок на основе молекул с закрытым и с открытым пятичленным циклом отличается на несколько порядков $[1,4]$. Это дает возможность рассматривать пленки фталидов в качестве материалов для разработки молекулярных электрических переключателей - важного направления современной органической электроники [6,7]. При исследовании модельных систем на основе фталидов было показано, что для раскрытия пятичленного цикла необходимо преодолеть потенциальный барьер, а в результате раскрытия происходит понижение энергии на несколько десятых долей $\mathrm{eV}$ [8]. Преодоление такого потенциального барьера может произойти в присутствии избыточного заряда. Например, избыточный отрицательный заряд в молекуле формируется при исследованиях диссоциативного захвата электронов из падающего электронного пучка $[5,8]$. Избыточный заряд может также быть инжектирован или перенесен через интерфейс в пленку фталида из твердотельной подложки. Действительно, физикохимическое взаимодействие на границе органического материала и твердотельной поверхности может способствовать упорядочиванию молекул в органическом слое, сопровождаться переносом электронного заряда, изменением электронной работы выхода поверхности, изменением структуры максимумов плотности электронных состояний валентной зоны и зоны проводимости [9-11]. 
В числе экспериментальных методик исследования незаполненных электронных состояний органических соединений отметим методики, направленные на исследования резонансного захвата электронов молекулами в газовой фазе $[8,12]$, и метод спектроскопии полного тока (TCS - Total Current Spectroscopy) [13], позволяющий также изучать перенос электронного заряда при осаждении сверхтонких органических покрытий на поверхность твердого тела. Поверхность высокоупорядоченного пиролитического графита (HOPG - Highly Oriented Pyrolytic Graphite) демонстрирует хорошо воспроизводимые значения электронной работы выхода около $4.6 \mathrm{eV}$ [14], поэтому она достаточно удобна для использования в качестве подложки для нанесения органического материала. В настоящей статье приведены результаты исследования методом TCS незаполненных электронных состояний зоны проводимости ультратонких пленок дифенилфталида (DPP — Diphenylphthalide) на поверхности высокоупорядоченного пиролитического графита. Приведены результаты по диагностике атомного состава пленки DPP и по исследованию формирования потенциального барьера на границе пленки DPP и HOPG подложки.

\section{2. Эксперимент}

Для формирования пленок использовали реактивы дифенилфталида, DPP (рис. 1), идентичные исследованным в работе [8]. Синтез DPP проводили следующим образом. Фталевый ангидрид $(170 \mathrm{~g})$ кипятили в бензоле $(780 \mathrm{ml})$ в присутствии $\mathrm{AlCl}_{3}(306 \mathrm{~g})$ в течение $12 \mathrm{~h}$. Затем к смеси добавили $85 \mathrm{ml}$ уксусного ангидрида и кипятили еще $12 \mathrm{~h}$. Реакционную массу высадили в подкисленную $\mathrm{HCl}$ воду со льдом и отогнали избыток бензола с водяным паром. Смолообразные примеси из продукта экстрагировали небольшим количеством уксусной кислоты (вначале холодной, затем кипящей с фильтрованием после охлаждения). Продукт кристаллизовали из уксусной кислоты (с углем), промывали водой, кристаллизовали из этанола (с углем). Выход DPP составил 40-50\%. Температура плавления $T_{\text {melt }}$ составила $116-117^{\circ} \mathrm{C}$. Температура кипения $T_{\text {boil }}$ составила

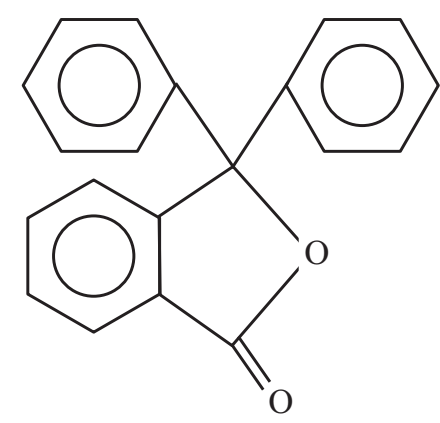

Рис. 1. Структурная формула молекул дифенилфталида (DPP). $210-220^{\circ} \mathrm{C}$ при давлении 250 Ра. Перед нанесением пленок в целях обезгаживания реактивы DPP выдерживали в аналитической камере при базовом давлении $10^{-6} \mathrm{~Pa}$ и температуре $100^{\circ} \mathrm{C}$ в течение $2-3 \mathrm{~h}$. Соответствие атомного состава органических покрытий химической формуле исследованных молекул подтверждено с помощью методики рентгеновской фотоэлектронной спектроскопии (XPS - X-ray Photoelectron Spectroscopy). Для этого использовали термически осажденные пленки толщиной около $50 \mathrm{~nm}$, приготовленные ex situ. Измерения проводили на комплексном фотоэлектронном спектрометре Escalab 250Xi (Thermo Fisher Scientific Inc.) с энергией фотонов $\mathrm{Al} K_{\alpha}=1486 \mathrm{eV}$. Поверхность HOPG подложки получали методом скола путем прикладывания и отрывания адгезионного пластика. Затем подложку помещали в аналитическую камеру и проводили дальнейшую очистку ее поверхности воздействием фокусированного пучка Хе лампы высокого давления. Это приводило к нагреву поверхности $\mathrm{HOPG}$ до $300^{\circ} \mathrm{C}$. После охлаждения подложки до комнатной температуры проводили осаждение пленок DPP толщиной до $10 \mathrm{~nm}$ со скоростью примерно $0.1 \mathrm{~nm} / \mathrm{min}$. Во время осаждения пленок допускали повышение давления в вакуумной камере на порядок от базового давления $\left(10^{-6} \mathrm{~Pa}\right)$.

Измерения электронных свойств пленок структуры HOPG/DPP проводили методом спектроскопии полного тока (TCS) $[13,15]$ в процессе увеличения толщины DPP покрытия до $10 \mathrm{~nm}$. При TCS измерениях тестирующий пучок электронов площадью поперечного сечения $0.2-0.4 \mathrm{~mm}^{2}$ направляли по нормали к исследуемой поверхности и с помощью lock-in усилителя регистрировали производную по энергии от полного тока $S(E)$, проходящего через образец. При этом энергию падающих электронов задавали в диапазоне от 0 до $25 \mathrm{eV}$ относительно уровня вакуума $\left(E_{\mathrm{vac}}\right)$ исследованной поверхности. TCS предоставляет возможность определять работу выхода исследуемой поверхности относительно уровня Ферми системы, то есть величину $\left(E_{\mathrm{vac}}-E_{\mathrm{F}}\right)$ с учетом калибровки инструмента [13]. Тонкая структура спектров полного тока (ТССПТ) отражает структуру расположения нижних границ особенностей плотности незаполненных электронных состояний (DOUS Density of Unoccupied Electronic States) в зоне проводимости $[13,16]$.

\section{3. Результаты и обсуждение}

Диагностику атомного состава пленок DPP проводили методом XPS. B XPS спектре поверхности пленок DPP, приготовленных ex situ, отчетливо наблюдались максимумы атомных компонент $\mathrm{C}_{1 \mathrm{~s}}$ и $\mathrm{O}_{1 \mathrm{~s}}$. Максимум $\mathrm{C}_{1 \mathrm{~s}}$ расположен при значении энергии связи $284.5 \mathrm{eV}$, что хорошо соответствует нахождению преобладающего количества атомов углерода в DPP в составе фенильных групп (рис. 1), то есть в $s p^{2}$-гибридизованном состоянии [17-19]. Максимум $\mathrm{O}_{1 \mathrm{~s}}$, исходящий от пленок 
DPP, расположен при значении энергии связи $532 \mathrm{eV}$. Такое энергетическое положение соответствует атомам кислорода, связанным одинарной либо двойной связью с алифатическим атомом углерода $[20,21]$, что согласуется со структурой DPP (рис. 1). С учетом относительных интенсивностей измеренных $\mathrm{C}_{1 \mathrm{~s}}$ и $\mathrm{O}_{1 \mathrm{~s}} \mathrm{XPS}$ максимумов и факторов чувствительности их регистрации [18] отношение концентраций атомов С и О составило примерно 10 к 1. Это вполне соответствует химической формуле молекул DPP. При этом следует учитывать и 15-20\% погрешность в определении атомного состава, связанную с адсорбцией на поверхность пленок кислород-содержащих и углерод-содержащих примесей из воздуха [21,22].

Серия зависимостей тонкой структуры спектров полного тока (ТССПТ), измеренная в процессе осаждения пленок DPP на HOPG поверхность, представлена на рис. 2. ТССПТ, измеренные при толщине органического покрытия $0 \mathrm{~nm}$, исходят от HOPG подложки и имеют характерный профиль с минимумом в области $11 \mathrm{eV}$ и максимумом в области $19 \mathrm{eV}$ выше $E_{\mathrm{F}}$. Аналогичная TССПТ поверхности HOPG наблюдалась нами ранее

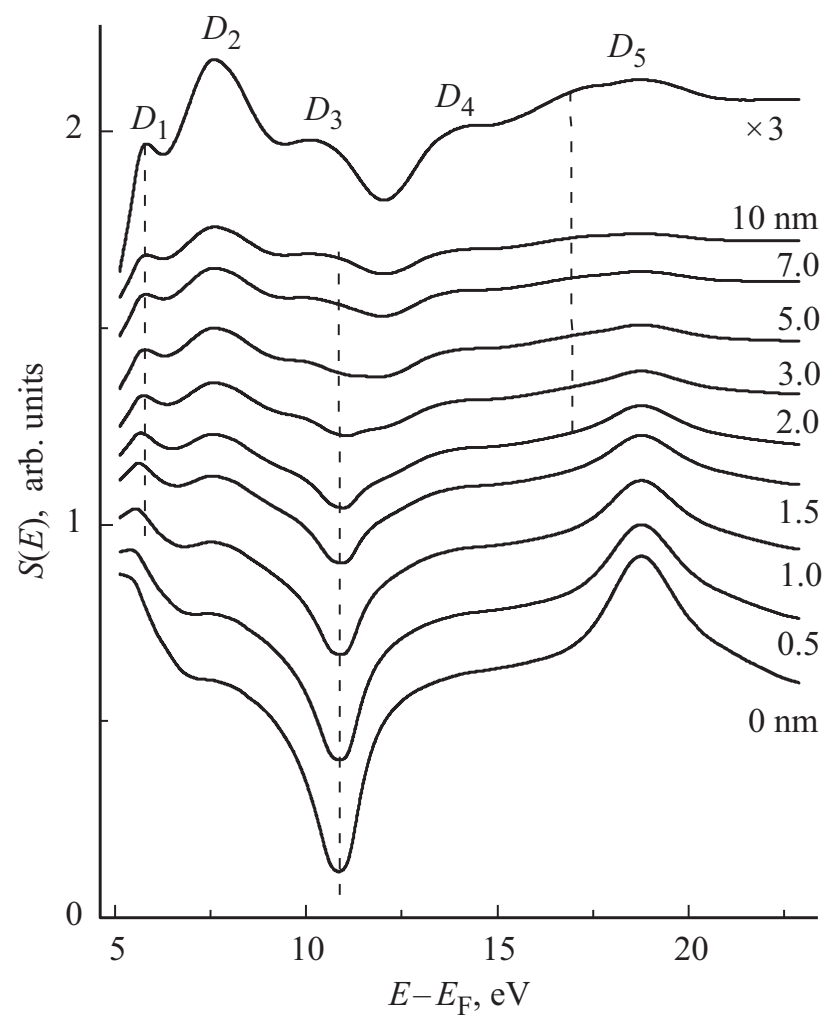

Pис. 2. ТССПТ в процессе осаждения пленок DPP на поверхность HOPG. $D_{1}-D_{5}-$ максимумы ТССПТ, характерные для пленок DPP. Подписи около кривых указывают соответствующую толщину органического покрытия. ТССПТ при толщине покрытия $10 \mathrm{~nm}$ представлена также и в увеличенном в 3 раза масштабе, обозначено символом $\times 3$. Вертикальные пунктирные линии показаны для удобства сравнения положений максимумов.
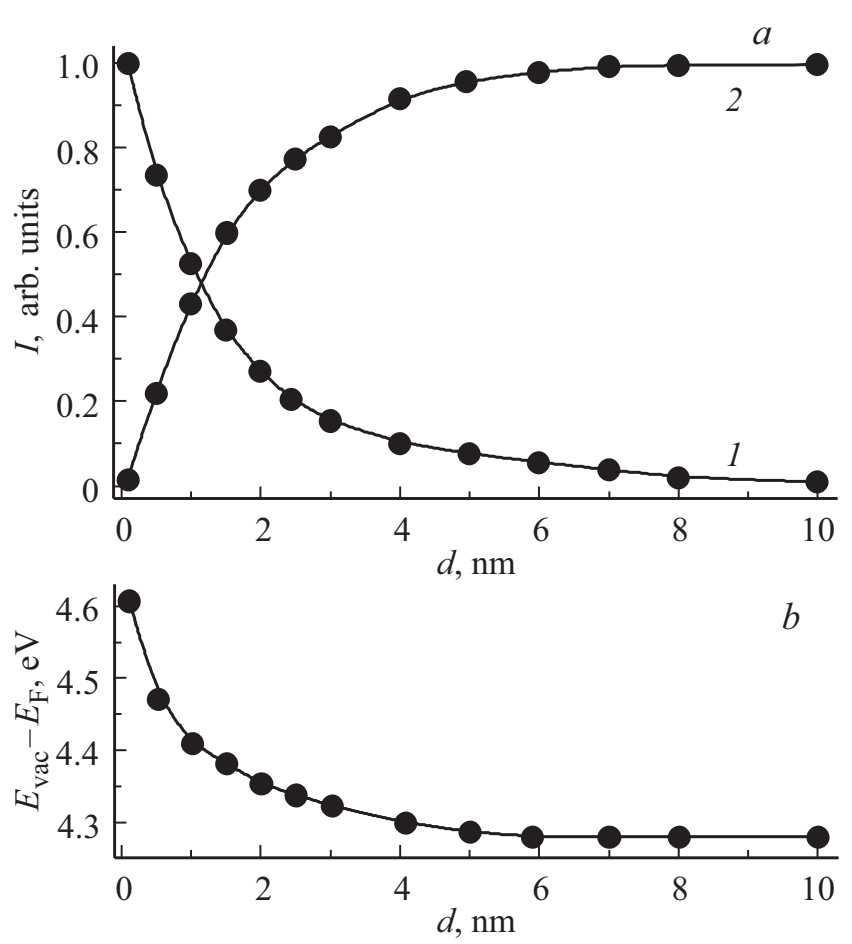

Рис. 3. Анализ TCS результатов при формировании DPP пленки на поверхности HOPG. a) уменьшение интенсивности ТССПТ подложки (кривая 1) и нарастание интенсивности ТССПТ пленки DPP (кривая 2). $b$ ) изменение положения уровня вакуума $E_{\mathrm{vac}}$ относительно $E_{\mathrm{F}}$ в зависимости от толщины осажденного слоя DPP.

при исследованиях методом TCS [23] и соответствует результатам исследований DOUS поверхности HOPG методом спектроскопии края поглощения рентгеновских лучей (NEXAFS - Near Edge X-ray Absorption Fine Structure) и теоретических расчетов [24,25]. В процессе осаждения DPP пленки ТССПТ подложки затухала, и одновременно нарастала интенсивность новой ТССПТ (рис. 2). При толщине пленки более $5 \mathrm{~nm}$ сформировалась стабильная ТССПТ поверхности с характерными максимумами $D_{1}(6 \mathrm{eV}), D_{2}(7.5 \mathrm{eV}), D_{3}(10.5 \mathrm{eV}), \mathrm{D} 4$ $(14 \mathrm{eV})$ и достаточно широким максимумом $D_{5}$, в котором можно выделить два компонента при 17 и $18.5 \mathrm{eV}$. При увеличении толщины DPP покрытия до $10 \mathrm{~nm}$ ТССПТ практически не изменялась. А при дальнейшем осаждении пленки наблюдалось размытие максимумов и сдвиг их энергетического положения, что следует связывать с накоплением заряда на поверхности под действием падающего электронного пучка $[13,23]$.

Для исследования процесса формирования DPP пленки в процессе ее осаждения проведен анализ изменения интенсивностей основных максимумов ТССПТ НОРG подложки и DPP пленки (рис. 3, $a$ ). Оценку интенсивностей максимумов ТССПТ проводили аналогично методу, рассмотренному в работах $[23,26]$. Так, для анализа увеличения интенсивности ТССПТ пленки DPP был выбран достаточно отчетливый максимум $D_{2}$ (рис. 2). 
Для анализа затухания особенностей HOPG подложки целесообразно выбрать разницу значений $S(E)$ в области минимума при $11 \mathrm{eV}$ и горизонтального участка ТССПТ HOPG подложки при $7.5 \mathrm{eV}$. В случае формирования сплошного органического покрытия следует ожидать экспоненциального роста интенсивностей ТССПТ осаждаемого покрытия и затухания особенностей ТССПТ подложки с изменением толщины покрытия $(d)$. Показатель этой экспоненциальной зависимости дается выражением $-2 d / \lambda$, как обсуждалось ранее в работах $[13,23]$, где $\lambda$ - длина свободного пробега электронов при данной энергии падающего электрона. При энергии электрона $11-12 \mathrm{eV}$ выше $E_{\mathrm{F}}$ значение $\lambda$ составляет приблизительно $3 \mathrm{~nm}$, а при энергии $7-8 \mathrm{eV}-$ приблизительно $4 \mathrm{~nm}[13,27]$. Зависимости изменения интенсивностей основных максимумов ТССПТ от толщины пленки DPP (рис. 3) в целом соответствуют вышеупомянутым экспоненциальным зависимостям, что свидетельствует о формировании сплошного слоя DPP на HOPG подложке. Следует отметить, что появление максимумов $D_{1}-D_{5}$ (рис. 2 и 3 ) наблюдается на ранней стадии осаждения, когда толщина осажденного слоя DPP еще не достигла $1 \mathrm{~nm}$. Таким образом, молекулы в слое DPP, находящиеся в непосредственном контакте c поверхностью подложки демонстрируют структуру максимумов ТССПТ, аналогичную более толстой пленке DPP. Это наблюдение соответствует тому, что воздействие поверхности HOPG не изменило электронную структуру молекул DPP, что наблюдалось и ранее для других интерфейсов органических пленок с подложками малой реакционной способности $[26,28,29]$.

Значение электронной работы выхода исследованной поверхности, то есть значение $E_{\mathrm{vac}}$ поверхности относительно $E_{\mathrm{F}}$, регистрируется экспериментально как энергетическое положение первичного TCS максимума. Значение энергии первичного TCS максимума отражает пороговое значение энергии электронов в падающем пучке, при котором они могут достичь исследуемую поверхность. Численные значения работы выхода можно определить в результате калибровки TCS инструмента на известных поверхностях. Так для поверхности атомно-чистого $\mathrm{Au}$ характерно значение работы выхода $5.2 \mathrm{eV}$ [14], а для поверхности HOPG - примерно $4.6 \mathrm{eV}[14,23]$. Изменение значения $E_{\mathrm{vac}}-E_{\mathrm{F}}$ в процессе формирования интерфейса $\mathrm{HOPG} / \mathrm{DPP}$ показано на рис. $3, b$. Значение $E_{\mathrm{vac}}-E_{\mathrm{F}}$ исходной поверхности составило приблизительно $4.6 \mathrm{eV}$. С учетом размытия энергий электронов в тестирующем пучке и конечной ширины первичного TCS максимума погрешность определения значений $E_{\mathrm{vac}}-E_{\mathrm{F}}$ составляет $0.1 \mathrm{eV}$. При увеличении толщины DPP пленки до 5-7 nm наблюдалось понижение работы выхода на $0.3 \mathrm{eV}$ (рис. $3, b$ ). Таким образом, экспериментально установленные значения работы выхода пленок DPP составили $4.3 \pm 0.1 \mathrm{eV}$. Из литературных данных известно, что при достаточно слабом взаимодействии на границе подложка/органическая пленка значение работы выхода органической пленки при толщине покрытия более $5 \mathrm{~nm}$ не зависит от выбора подложки, причем в большом количестве случаев формирование значения работы выхода происходит в еще более узком слое, толщиной $1-3 \mathrm{~nm}$ [28-30]. Понижение значений $E_{\mathrm{vac}}-E_{\mathrm{F}}$ при осаждении пленки соответствует избытку положительного заряда в пленке, то есть переносу отрицательного заряда из DРP пленки в HOPG подложку. Согласно предположениям, сделанным в работах $[5,8]$, существенное изменение электропроводности материалов на основе молекул фталидов обусловлено разрывом связи $\mathrm{C}-\mathrm{O}$ в составе пятичленного цикла фталида. Одним из условий раскрытия пятичленного цикла фталида является присутствие дополнительного электронного заряда вблизи молекул фталидов [8]. В случае исследованной нами структуры HOPG/DPP влияние HOPG поверхности не способствует выполнению этого условия, так как, напротив, способствует обеднению пленки DPP электронным зарядом.

Как упоминалось в разд. 2, максимумы ТССПТ отражают структуру расположения нижних границ особенностей DOUS $[13,16]$. Поэтому установление $\pi^{*}$ или $\sigma^{*}$ характера наблюдаемых максимумов $D_{1}-D_{5}$ в ТССПТ пленок DPP (рис. 2) представляет определенный фундаментальный интерес. Результатов исследований DOUS пленок DPP во всем интересующем диапазоне энергий от 5 до $20 \mathrm{eV}$ выше $E_{\mathrm{F}}$ в литературе обнаружено не было. Однако в работе [8] был проведен расчет энергий расположения четырех низколежащих $\pi^{*}$ орбиталей молекул DPP. Для установления расположения этих орбиталей относительно $E_{\mathrm{F}}$ было учтено установленное в данной работе значение работы выхода поверхности пленки DPP $(4.3 \mathrm{eV})$ и учтено значение энергии поляризации среды в конденсированном состоянии, характерное для полупроводниковых органических пленок $1.2 \mathrm{eV}$ [31]. Так, относительно $E_{\mathrm{F}}$ четыре низколежащие $\pi^{*}$ орбитали молекул DPP расположены при энергиях $4.42 \mathrm{eV}, 4.91 \mathrm{eV}$, $6.76 \mathrm{eV}, 9.14 \mathrm{eV}$. Сравним энергетическое расположение этих орбиталей с расположением максимумов $D_{1}-D_{5}$ в ТCCПТ пленок DPP (рис. 2). Две орбитали при 4.42 и $4.91 \mathrm{eV}$ расположены ниже энергетического диапазона, охватываемого ТССПТ. А орбитали при $6.76 \mathrm{eV}$ и $9.14 \mathrm{eV}$ соответствуют расположению максимумов $D_{1}$ и $D_{2}$ ТССПТ. Таким образом, максимумы $D_{1}$ и $D_{2}$ можно связать с границами зон $\pi^{*}$ электронных состояний DOUS пленок DPP.

\section{4. Заключение}

В результате XPS исследований пленок DPP, термически осажденных на поверхность HOPG, обнаружены максимумы остовных уровней $\mathrm{C}_{1 \mathrm{~s}}$ и $\mathrm{O}_{1 \mathrm{~s}}$. Отношение концентраций этих атомов в пленке DPP хорошо соответствует химической формуле DPP молекул. Установлены закономерности формирования незаполненных электронных состояний пленок DPP толщиной до $10 \mathrm{~nm}$ на поверхности HOPG при использовании методики TCS 
в энергетическом диапазоне от 5 до $20 \mathrm{eV}$ выше $E_{\mathrm{F}}$. Низкоэнергетические максимумы ТССПТ $D_{1}(6 \mathrm{eV})$ и $D_{2}(7.5 \mathrm{eV})$ следует ассоциировать с границами зон $\pi^{*}$ электронных состояний DOUS пленок DPP. Экспериментально установленные значения энергии $E_{\mathrm{vac}}$ относительно $E_{\mathrm{F}}$, то есть электронной работы выхода пленок DPP, при толщине пленки 5-10 nm составляют $4.3 \pm 0.1 \mathrm{eV}$.

\section{Финансирование работы}

TCS и XPS исследования DPP выполнены при поддержке гранта Российского Научного Фонда № 19-1300021. Диагностика HOPG выполнена при поддержке РФФИ (18-03-00020). В работе использовали оборудование научного парка СПбГУ „Физические методы исследования поверхности“.

\section{Конфликт интересов}

Авторы заявляют, что у них нет конфликта интересов.

\section{Список литературы}

[1] А.Н. Лачинов, Н.В. Воробьева. УФН 176, 249 (2006).

[2] N. Johansson, A.N. Lachinov, S. Stafstrom, W.R. Salaneck. Synth. Met. 67, 319 (1994).

[3] А.Р. Юсупов, А.Н. Лачинов, Л.Р. Калимуллина, Р.М. Гадиев, Д.В. Никитина. ФТТ 61, 581 (2019).

[4] А.Н. Лачинов, Э.Р. Жданов, Р.Г. Рахмеев, Р.Б. Салихов, В.А. Антипин. ФТТ 52, 181 (2010).

[5] N.L. Asfandiarov, S.A. Pshenichnyuk, A.S. Vorob'ev, E.P. Nafikova, A.N. Lachinov, V.A. Kraikin, A. Modelli. J. Chem. Phys. 142, 174308 (2015).

[6] A.N. Aleshin, P.S. Krylov, A.S. Berestennikov, I.P. Shcherbakov, V.N. Petrov, V.V. Kondratiev, S.N. Eliseeva. Synth. Met. 217, 7 (2016).

[7] П.С. Крылов, А.С. Берестенников, С.А. Фефелов, А.С. Комолов, А.Н. Алешин. ФТТ 58, 2476 (2016).

[8] Н.Л. Асфандиаров, С.А. Пшеничнюк, Р.Г. Рахмеев, А.Н. Лачинов, В.А. Крайкин. ЖТФ 88, 1085 (2018).

[9] B. Handke, L. Klita, W. Niemiec. Surf. Sci. 666, 70 (2017).

[10] A.S. Komolov, E.F. Lazneva, S.N. Akhremtchik. Appl. Surf. Sci. 256, 2419 (2010).

[11] M. Krzywiecki, L. Grzadziel, P. Powroznik, M. Kwoka, J. Rechmann, A. Erbe. Phys. Chem. Chem. Phys. 20, 16092 (2018).

[12] S.A. Pshenichnyuk, A. Modelli, E.F. Lazneva, A.S. Komolov. J. Phys. Chem. A 120, 2667 (2016).

[13] A.S. Komolov, E.F. Lazneva, S.N. Akhremtchik, N.S. Chepilko, A.A. Gavrikov. J. Phys. Chem. C 117, 24, 12633 (2013).

[14] J. Hwang, A. Wan, A. Kahn, Mater. Sci. Eng. R 64, 1 (2009).

[15] A.S. Komolov, P.J. Moeller. Appl. Surf. Sci. 244, 573 (2005).

[16] I. Bartos. Progr. Surf. Sci. 59, 197 (1998).

[17] A.S. Komolov, K. Schaumburg, P.J. Moeller, V.V. Monakhov. Appl. Surf. Sci. 142, 591 (1999).

[18] J.F. Moulder, W.F. Stickle, P.E. Sobol, K. Bomben. Handbook of $X$-ray Photoelectron Spectroscope. 2nd ed. / Ed. J. Chastain. Eden Prairie: Perkin-Elmer Corporation (Physical Electronics) (1992).
[19] А.С. Комолов, Э.Ф. Лазнева, Н.Б. Герасимова, В.С. Соболев, Ю.А. Панина, С.А. Пшеничнюк, Н.Л. Асфандиаров. ФTT 61, 598 (2019).

[20] A. Ganguly, S. Sharma, P. Papakonstantinou, J. Hamilton. J. Phys. Chem. C 115, 17009 (2011).

[21] A.S. Komolov, Y.M. Zhukov, E.F. Lazneva, A.N. Aleshin, S.A. Pshenichnuk, N.B. Gerasimova, Yu.A. Panina, G.D. Zashikhin, A.V. Baramygin. Mater. Des. 113, 319 (2017).

[22] И.А. Аверин, А.А. Карманов, В.А. Мошников, И.А. Пронин, С.Е. Игошина, А.П. Сигаев, Е.И. Теруков. ФТТ 12, 2304 (2015).

[23] A.S. Komolov, P.J. Møller, E.F. Lazneva. J. Electr. Spec. Rel. Phen. 131-132, 67 (2003).

[24] A.S. Komolov, P.J. Møller. Synth. Met. 138, 119 (2003).

[25] R.A. Rosenberg, P.J. Love, V. Rehn. Phys. Rev.B 33, 4034 (1986).

[26] А.С. Комолов, Э.Ф. Лазнева, Н.Б. Герасимова, Ю.А. Панина, А.В. Барамыгин, Г.Д. Зашихин, С.А. Пшеничнюк. ФТТ 58, 367 (2016).

[27] T. Graber, F. Forster, A. Schoell, F. Reinert. Surf. Sci. 605, 878 (2011).

[28] A.L. Shu, W.E. McClain, J. Schwartz, A. Kahn. Organic Electron. 15, 2360 (2014).

[29] S. Braun, W. Salaneck, M. Fahlman. Adv. Mater. 21, 1450 (2009).

[30] I.G. Hill, J. Schwartz, A. Kahn. Organic Electr. 1, 5 (2000).

[31] I.G. Hill, A. Kahn, J. Cornil, D.A. dos Santos, J.L. Bredas. Chem. Phys. Lett. 317, 444 (2000).

Редактор К.В. Емцев 